\title{
Ensino de Química com abordagem CTS - elaboração e vivência de uma sequência didática com a temática mineração.
}

\author{
Chemistry Teaching with a CTS approach - elaboration and experience of a didactic \\ sequence with the mining theme.
}

\author{
Lelise Francisca da Silva Fidelis ${ }^{1}$, Regina Simplício Carvalho ${ }^{2}$
}

\begin{abstract}
RESUMO: Este trabalho foi desenvolvido ao longo do Mestrado Profissional em Química em Rede Nacional (PROFQUI) no polo da Universidade Federal de Viçosa, com o objetivo de elaborar e testar um produto educacional para o ensino de Química com abordagem CTS (Ciência Tecnologia - Sociedade). Compõe o produto educacional uma sequência didática com a temática mineração. A importância e os reflexos sociais, econômicos e ambientais da atividade mineradora para a sociedade e, em especial para a comunidade de Caeté/MG, foram abordados. Conceitos relacionados à mineração, a importância do ferro na alimentação e suas aplicações foram também trabalhados. Várias metodologias de ensino foram propostas para o desenvolvimento do tema ao longoda sequência didática que compõem o produto educacional. Foram propostos trabalhos em grupos, sala de aula invertida, visitas em espaços não formais de educação, aulas práticas e atividades avaliativas, entre outras. Uma prévia do produto educacional foi aplicada em uma turma do Ensino Médio da Educação Básica, e teve como principal foco desenvolver uma aprendizagem significativa e relacionar a vivência dos alunos com a temática proposta, tornando-os cidadãos críticos em relação a atividade mineradora na região e no mundo.
\end{abstract}

Palavras-chave: Ensino de Química, Sequência didática, Mineração.

ABSTRACT: This work was carried out during the Professional Master's Degree in Chemistry in the National Network (PROFQUI) at the Federal University of Viçosa center, intending to develop and test an educational product for Chemistry teaching with a CTS approach. The elaborated product was applied in High School Classes of basic education, and its main focus is to develop a meaningful learning and relate the students experience with the proposed theme, making these citizens critical in relation to mining activities in the region and in the world. The theme addressed in the didactic sequence was mining, in which the social, economic and environmental reflexes and importance of mining activity was studied for society, especially for the community of Caeté / MG. Concepts related to mining, the importance of iron in food and its applications. Several teaching methodologies were used in classes that set the educational product, such as group work, inverted classroom, visits to non-formal educational spaces, practical classes and evaluative activities.

Keywords:Chemistry teaching, Didactic sequence, Mining.

\footnotetext{
1 Professora da Secretaria de Estado e Educação de Minas Gerais. Mestre em Química pela Universidade Federal de Viçosa - ORCID: https://orcid.org/0000-0001-6789-0739. E-mail: lelisequimica@yahoo.com.br Agradecimento à CAPES pela bolsa concedida.

2 - Professora do Departamento de Química - Universidade Federal de Viçosa - ORCID: https://orcid.org/0000-00020679-4070. Email: resicar@ufv.br
} 


\section{INTRODUÇÃO}

Aprender Química consiste não apenas em conhecer suas teorias e seus conteúdos, mas também em compreender seus processos e linguagens, assim como o enfoque e o tratamento empregado por essa área da ciência no estudo dos fenômenos. A química possui uma forma peculiar de ver o mundo, diversa daquela que os estudantes estão habituados a utilizar. Mesmo que um estudante não empregue o pensamento químico, ao abordar sua realidade ou linguagem química, ao se comunicar, ou seja, mesmo que ele não adote uma visão de mundo caracterizada como científica, segundo El-Hani e Bizzo (2002), apenas compreender essa abordagem já é um processo bastante complexo (MARCONDES et al., 2014).

Tendo-se em vista que a visão de mundo norteia todos os atos de conhecimento, torna-se clara sua importância para o Ensino de Ciências (EL-HANI e BIZZO, 2002). Para se tornar efetivo, o ensino de Química deve ser problematizador, desafiador e estimulador, de maneira que seu objetivo seja o de conduzir o estudante à construção do saber científico. Não se pode mais conceber um ensino de Química que simplesmente apresenta questionamentos pré-concebidos e com respostas acabadas. É preciso que o conhecimento químico seja apresentado ao aluno de uma forma que o possibilite interagir ativa e profundamente com o seu ambiente, entendendo que este faz parte de um mundo do qual ele também é ator e corresponsável (LIMA, 2012).

A integração dos significados produzidos pela Química nos significados cotidianos já anteriormente elaborados pelos alunos é, em essência, o que constitui aprender Química. Contudo, aprender Química é ampliar entendimentos de senso comum dos fenômenos com a inserção de significados produzidos no discurso científico e, mais especificamente, no discurso da Química. (GALIAZZI;MORAES; ROQUE, 2010).

A contextualização no ensino de ciências vem sendo defendida por orientações oficiais, educadores e pesquisadores como um princípio norteador de uma educação voltada para a cidadania que possibilite a aprendizagem significativa de conhecimentos científicos e a intervenção consciente, e também está relacionada ao movimento Ciência, Tecnologia e Sociedade (CTS). A contextualização no ensino de Ciências que privilegia o estudo de contextos sociais com aspectos políticos, econômicos e ambientais, fundamentado em conhecimentos das ciências e tecnologia, é fundamental para desenvolver um ensino que venha a contribuir para a formação de um aluno crítico, atuante e sempre que possível transformador de sua realidade desfavorável (MARCONDES; SILVA, 2010). Assim será elaborada uma sequência didática com a temática Mineração com abordagem CTS (Ciência, Tecnologia e Sociedade), contextualizada que trabalha a interdisciplinaridade e que tem como principal objetivo desenvolver uma visão crítica dos alunos sobre a atuação da mineração na cidade de Caeté e sobre as questões ambientais relacionadas a essa atividade. Com base no exposto, a temática Mineração foi escolhida no presente trabalho pois está diretamente relacionada com os moradores da cidade de Caeté, sendo que a região possui várias empresas mineradoras e uma delas está localizada próxima a um dos principais pontos turísticos da cidade. Esse tema está sempre sendo discutido pelos moradores e autoridades devido ao grande impacto ambiental provocado na cidade, mas também pela importância na geração de emprego e renda para o município. 


\section{ASPECTOS METODOLÓGICOS DO TRABALHO}

O presente trabalho tem uma abordagem qualitativa, que busca compreender os fenômenos sociais (GERHARDT, SILVEIRA, 2009), com destaque para pesquisas bibliográficas, em livros e artigos, sobre fatos históricos da cidade de Caeté, sobre a mineração na região do município, assim como dos aspectos químicos, socioculturais e ambientais envolvidos nos processos. A sequência didática foi estruturada e a sua aplicação adaptada às condições da escola e da turma escolhida. A expectativa era de que tratando-se de um processo dinâmico, no decorrer da aplicação seriam feitos ajustes conforme a demanda e as alterações no calendário da escola. As impressões coletadas pela professora durante a aplicação da sequência seriam registradas em um diário de bordo.

\section{FUNDAMENTAÇÃO TEÓRICA}

\section{NOS CAMINHOS DO OURO}

Caeté, no Estado de Minas Gerais, é uma das cidades mineiras que tem sua história e seu surgimento imbricado com a busca pelo ouro durante o período colonial (TRINDADE; VIEIRA, 2018).A cidade de Caeté tem sua origem no início do ciclo do ouro. Em meados do século XVII, surgiram em Minas Gerais os primeiros aventureiros que vinham do litoral em busca pelo ouro, prata e pedras preciosas. A primeira bandeira a pisar o solo do atual município teria sido a do paulista Leonardo Nardezem 1701, que é citado como o descobridor de Caeté. Este veio para a região de Caeté atraído pela riqueza aurífera da região (CAETÉ, 2017). Devido à grande quantidade de ouro em seu território, a Vila passou a receber um grande fluxo de desbravadores, em sua maioria paulistas, buscando riquezas, o que contribuiu, diretamente, para o crescimento da população e, consequentemente, o desenvolvimento urbano.

Ao final do século XVIII acontece o esgotamento das aluviões na região e a cidade passou por um profundo declínio econômico com o fim de sua principal atividade econômica. Este declínio altera profundamente o modo de vida dos habitantes forçando muitos a buscar formas de sustento em outras comunidades ou assumir outra alternativa, esta, mais comum, a agricultura. Além da profunda estagnação econômica, por sua participação na Revolta Militar de Ouro Preto (PATARO, 2012, p. 43 apud TRINDADE; VIEIRA, 2018), a localidade tem o seu título de Vila suprimido. Desta forma, o século XIX, em quase sua totalidade, vai marcar este período de estagnação econômica. (TRINDADE; VIEIRA,2018).

Não obstante, Caeté segue o destino das demais cidades mineiras surgidas no período da mineração colonial que viveram o desenvolvimento inicial com a busca pelo ouro, a recessão econômica com o fim da mineração - que leva a modos de produção basicamente agrícolas - e, por fim, o desenvolvimento industrial do século XX (TRINDADE; VIEIRA, 2018). 
Assim sendo, Caeté que já havia vivenciado o ciclo do outro e o período da terra começou a entrar na era do ferro e na luta pelo progresso econômico no início do século XX. A primeira metade deste século, em particular, irá marcar a consolidação do processo industrial na cidade e, consequentemente, a retomada de seu desenvolvimento econômico (TRINDADE; VIEIRA, 2018).

O estado de Minas Gerais, quando falamos em mineração, faz toda a honra ao seu nome. O descobrimento do ouro nos primórdios do século XVII, trouxe um notável desenvolvimento na província de Minas Gerais, com a chegada de aventureiros, grupos organizados e membros da corte portuguesa no Brasil (FONSECA e SOBREIRA,2001) e ainda hoje Minas Gerais é o estado que mais produz minério (REZENDE, 2016).

Caeté é uma cidade que faz parte do Quadrilátero Ferrífero, que de acordo com Machado e Ruchkys (2013) é internacionalmente reconhecido como uma das maiores províncias minerais do planeta.

O Quadrilátero Ferrífero localiza-se na porção centro-sudeste do Estado de Minas Gerais. Com área de cerca de $7.000 \mathrm{~km}^{2}$, abrange parte dos municípios de Bom Jesus do Amparo, São Gonçalo do Rio Abaixo, Barão de Cocais, Santa Bárbara, Catas Altas, Alvinópolis, Mariana, Ouro Preto, Ouro Branco, Congonhas, Jeceaba, Belo Vale, Moeda, Itabirito, Rio Acima, Brumadinho, Mario Campos, Sarzedo, Ibirité, Nova Lima, Raposos, Sabará, Caeté, Belo Horizonte e Santa Luzia, como apresentado na Figura 01 (MACHADO e RUCHKYS, 2013).

Figura 01: Mapa com os municípios que integram o Quadrilátero Ferrífero

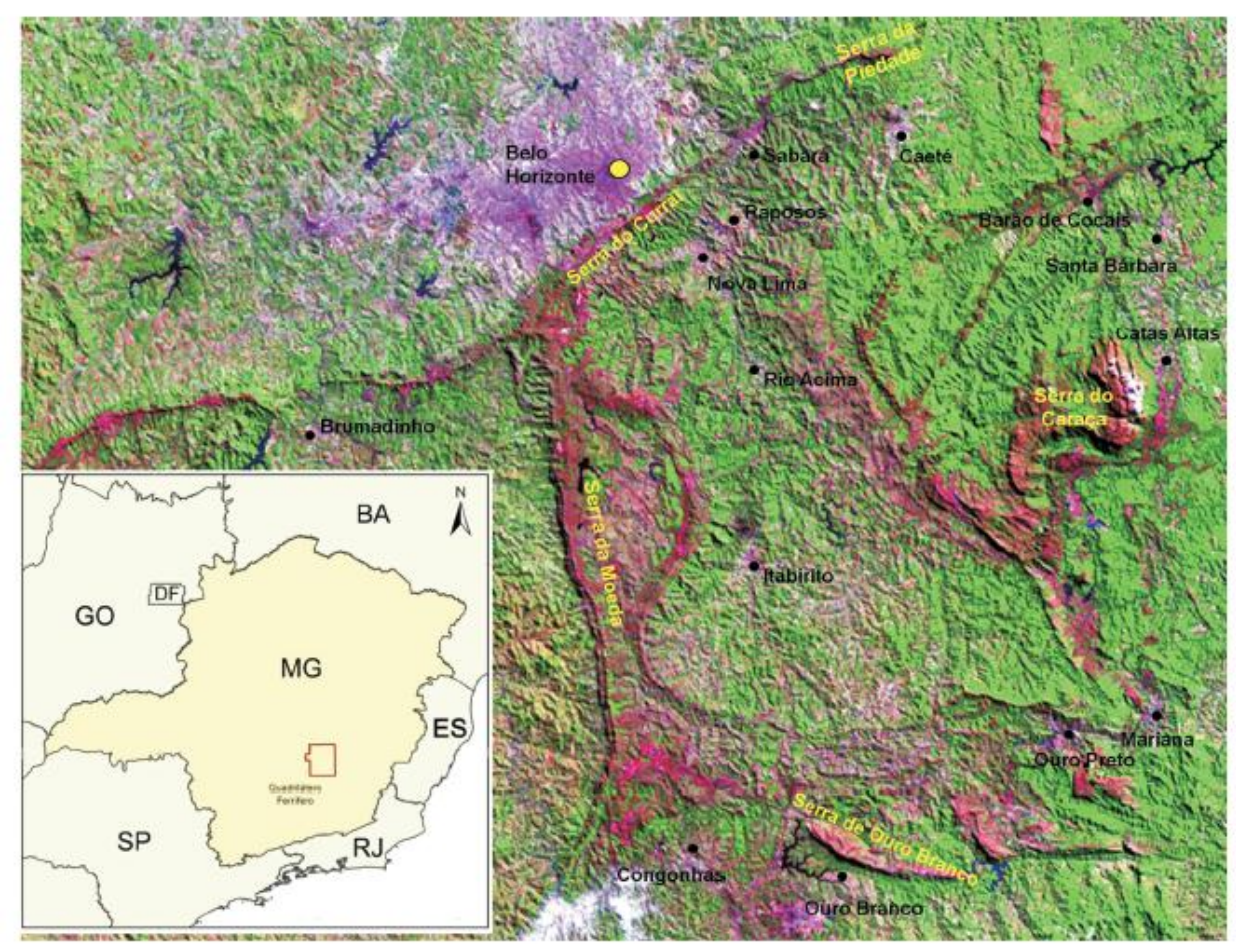

Fonte: Machado e Ruchkys, 2013, p.121 


\section{MINERAÇÃO: CRESCIMENTO ECONÔMICO E CONFLITOS AMBIENTAIS}

A importância da mineração na economia brasileira é histórica. A atividade pontua a trajetória sociopolítica do país, tendo estado presente, de diferentes formas, durante os três regimes políticos pelos quais o Brasil passou de 1500 até hoje (ARAÚJO; FERNANDES, 2016).

A mineração é um dos setores básicos da economia do país, contribuindo de forma decisiva para o bem-estar e a melhoria da qualidade de vida das presentes e futuras gerações, sendo fundamental para o desenvolvimento de uma sociedade equânime, desde que seja operada com responsabilidade social, estando sempre presentes os preceitos do desenvolvimento sustentável. É importante reconhecer e manter sob controle os impactos que esta atividade provoca no meio ambiente, assim proporcionando um meio ambiente adequado para as futuras gerações que estão por vir (SILVA, 2007).

A indústria mineral tem crescido a ritmo acelerado - tanto em volumes extraídos, quanto pela abertura de novas minas, que, em geral, são autorizadas apenas pelo poder central, excluindo-se os moradores locais (ARAÚJO; FERNANDES, 2016). De acordo com Bitar (1997, apud REZENDE, 2016) a mineração é responsável por promover uma diversidade de efeitos não desejados, os impactos de grande relevância seriam: alterações ambientais, conflitos de uso do solo, depreciação de imóveis circunvizinhos, geração de áreas degradadas e transtornos ao tráfego urbano. Estes provocam conflitos com a comunidade, devido à falta de interesse do empreendimento em atender as necessidades da população (REZENDE, 2016).

Segundo Enríquez (2007, apud REZENDE, 2016), a mineração apenas pode ser considerada sustentável se minimizar os seus impactos ambientais e mantiver certos níveis de proteção ecológica e de padrões de qualidade ambientais, além de garantir o bem-estar socioeconômico no presente. Cowell et al., (1999 apud REZENDE, 2016) defende que a sustentabilidade na mineração deve ser discutida sob duas perspectivas contrastantes baseadas em aspectos ecológicos, sociais e econômicos, acerca da indústria extrativa mineral (REZENDE, 2016).

A negativa das populações a projetos mineradores que, segundo suas percepções, possam colocar em risco a sua qualidade de vida e saúde, bem como o meio ambiente, têm crescido em todo o mundo. Numa tentativa de obter a chamada licença social para operar, muitas empresas têm adotado estratégias para ampliar o diálogo com a sociedade e melhorar a governança sobre os projetos de mineração (ARAÚJO; FERNANDES, 2016).

\section{FERRO: UM ELEMENTO UNIVERSAL}

Ferro (deriva do latim ferrum) é bastante utilizado pelo homem em todo o mundo, sendo pouco provável que haja pessoas, no mundo civilizado, que não conheçam ao menos um objeto que contenha ferro em sua constituição, pois esse metal tem importante papel no desenvolvimento da sociedade (MEDEIROS, 2010). 
Dentre os oito elementos químicos mais abundantes na crosta terrestre, o ferro figura em quarto lugar com cerca de 5\% em massa. Os outros elementos são oxigênio (46,6\%), silício (26,72\%), alumínio $(8,13 \%)$, cálcio $(3,63 \%)$, sódio $(2,83 \%)$, potássio $(2,59 \%)$ e magnésio $(2,09 \%)$. Esses elementos correspondem aproximadamente a 97,59\% da massa da crosta terrestre (DUARTE, 2019).

O ferro apresenta propriedades químicas e físicas que o faz importante em processos químicos e físicos, no ambiente mineral e nos sistemas biológicos. A abundância do ferro, a relativa facilidade para a sua obtenção na forma de $\mathrm{Fe}(\mathrm{s})$, as suas propriedades mecânicas como maleabilidade, resistência e a sua fácil conformação o tornaram material de base para a fabricação de ferramentas e equipamentos (DUARTE, 2019).

O ferro é um dos metais amplamente utilizados pelos organismos vivos, participando de processos bioquímicos- metabólicos vitais, como síntese de DNA, RNA, proteínas, transporte de elétrons, respiração, proliferação celular e regulação da expressão gênica (LATUNDE-DADA, 1998, apud FREITAS; IZUMI; MACHADO, 2005).

Muitos seres vivos apresentam uma grande dependência por íon $\mathrm{Fe}^{2+,}$ uma vez que o centro de grupos heme, presentes na metaloproteína hemoglobina (o tipo mais comum é a homoglobina A) são constituídos por esse íon. A hemoglobina é a responsável pelo transporte de oxigênio dos pulmões aos tecidos celulares, onde ocorre a queima da glicose (para a queima desta é necessária a presença de oxigênio molecular, $\mathrm{O}_{2}$ ). Esse transporte ocorre graças ao íon $\mathrm{Fe}^{2+}$ da hemoglobina, que se combina com $\mathrm{O}_{2}$, em atmosfera rica nesse gás, possibilitando o seu transporte até as células, que é um ambiente rico em $\mathrm{CO}_{2}$, onde ocorre a troca do $\mathrm{O}_{2}$ por $\mathrm{CO}_{2}$. A partir desse ponto, a hemoglobina passa a transportar $\mathrm{CO}_{2}$ até os pulmões, onde encontra novamente uma região rica em $\mathrm{O}_{2}$, liberando assim o $\mathrm{CO}_{2}$ (MEDEIROS,2010).

Desde a Era do Ferro, há cerca de 1200-300 A.C., o ferro sempre esteve presente ao longo da história da humanidade. No nosso dia-a-dia, o ferro é encontrado em quase tudo que utilizamos, como em parafusos, utensílios de cozinha, ferramentas, transporte motorizado, máquinas, material de construção, navios, concreto armado dos viadutos, prédios e construções, nos aviões e em outras inúmeras aplicações (DUARTE, 2019).

A construção de uma abordagem em que os impactos da atividade mineral sejam minimizados é uma necessidade premente, enquanto os lucros da extração de um recurso natural finito que promovam a construção da prosperidade sustentável da região não for uma realidade. $\mathrm{O}$ aproveitamento dos rejeitos em aplicações secundárias carece de articulação com outras cadeias produtivas, como, por exemplo, da indústria cimenteira e da construção civil, mas, também, da viabilidade econômica. Políticas públicas devem ser criadas para as regiões mineradoras; a regulamentação e a implementação geridas por órgãos específicos devem sustentar as boas práticas internalizadas no planejamento físico-financeiro das empresas (DUARTE, 2019).

A extração do minério de ferro no país, pela sua magnitude e pelo protagonismo local, deve ser um eixo mobilizador de iniciativas dirigidas a inovação, ao desenvolvimento cientifico, a integração indústriasociedade, a capacitação de recursos humanos e ao desenvolvimento regional sustentável (DUARTE, 2019). 


\section{BENEFICIAMENTO DO MINÉRIO}

Inovações mais interessantes na área do tratamento de minérios ocorreram partir do século XVIII, início da Revolução Industrial com a invenção da máquina a vapor. Em meados do século XIX, por volta de 1864 a prática do tratamento de minério restringia-se ao ouro, cobre nativo e chumbo (FIGUEIRA; LUZ; ALMEIDA, 2010).

No final do século XIX e início do século XX ocorreram significativos desenvolvimentos na área de beneficiamento de minérios, como avanços tecnológicos ao desenvolvimento de design de equipamentos maiores e mais produtivos e eficientes (anos 40 - 70), ); à otimização de processos por meio de automação e computação (anos 70 - 90) a qual continua sendo uma área de grande desenvolvimento; e à racionalização do uso de energia nos anos 70, com a crise de aumento súbito dos preços de petróleo (FIGUEIRA; LUZ; ALMEIDA, 2010).

É notória a influência dos minerais sobre a vida e o desenvolvimento de um país principalmente com o aumento das populações que cada dia necessita de maior quantidade de matéria-prima para suprir as crescentes necessidades do ser humano. É difícil imaginar o nível material alcançado por nossa civilização, sem o uso dos minerais (FIGUEIRA; LUZ; ALMEIDA, 2010).

O minério de uma jazida é extraído por meio de operações de lavra (a céu aberto ou subterrânea) na mina. O que abastece a usina de tratamento é o produto da mina, o minério lavrado, ou seja, o ROM (run-of mine) (FIGUEIRA; LUZ; ALMEIDA, 2010). Apesar de ser essencialmente técnico em suas aplicações práticas, o tratamento de minérios, não pode desprezar o conceito econômico. Não é possível, na prática, obter uma separação completa dos constituintes minerais. Tem-se conhecimento que quanto maior o teor dos concentrados, maior é a perda, ou seja, mais baixas são as recuperações (LINS e LUZ, 2010).

Os métodos empregados são determinados para movimentar milhões de toneladas/ano, o que demanda espaço e água em abundância. A água advinda do rebaixamento do lençol freático no processo de cava da mina, em sua maioria é empregada na usina de beneficiamento. No fim do processo faz-se necessário reaver a água aplicada, com o intuito de ser reaproveitada durante os procedimentos, o que reduz consideravelmente a utilização de água ainda não demandada. Para diminuir o uso da água na usina e facilitar a disponibilidade hídrica na região é imprescindível reduzir a quantidade de água nos rejeitos e também ampliar a segurança das barragens de rejeito. Uma tendência que vem despontando é a disposição a seco de resíduos no processo de beneficiamento dos minérios (DUARTE, 2019).

Com a preocupação ligada à sustentabilidade que tem como objetivo suprir as necessidades de acordo com a demanda atual sem causar danos às gerações futuras, deve-se pensar no aproveitamento dos recursos minerais com o compromisso de priorizar os princípios de desenvolvimento sustentável. Isso remete a outras questões relativas ao aproveitamento consciente dos recursos naturais, resguardando-se o meio ambiente (FIGUEIRA; LUZ; ALMEIDA, 2010).

Hoje, existe uma cobrança cada vez mais abrangente para com os rejeitos da mineração de beneficiamento no sentido de evitarem danos aos terrenos. Para tal, sugere-se o preenchimento de minas 
(“back-fill”), restaurando as áreas mineradas cuidadosamente sem danificar o ambiente (FIGUEIRA; LUZ; ALMEIDA, 2010).

Nos processos de lavra e beneficiamento ocorre um acúmulo notável de massa de minério na produção mineral que se torna rejeito. Um impasse para a indústria mineral hoje é o descarte de rejeitos. Quanto às necessidades da sociedade de um modo geral por bens minerais, juntamente ao desenvolvimento econômico e tecnológico, acaba exigindo uma forma sustentável e economicamente coerente no aproveitamento de minérios de baixo teor ou mesmo aqueles de difícil beneficiamento. Tais procedimentos geram um aumento considerável na quantidade de rejeitos resultantes das produções, o que ultrapassa as atividades relacionadas aquelas com os próprios minérios (SOARES, 2010).

O desafio de produção, mais livre de impurezas, voltada a mecanismos de prevenção em torno dos processos, produtos gerados e os serviços, com o intuito de alcançar uma eficiência maior minimizar os impactos negativos tanto a saúde dos seres humanos como a degradação ambiental coloca os setores industriais e de serviços em alerta. A pesquisa e a tecnologia são áreas que merecem investimento constante e efetivo para que a mineração realize atividades com procedimentos menos impactantes (FIGUEIRA; LUZ; ALMEIDA, 2010).

\section{O APRENDER CIÊNCIAS}

O ensino de ciências, como parte da educação básica, tem como objetivo central a formação da cidadania, o que implica na necessidade de desenvolver no aluno conhecimentos básicos de ciência e tecnologia para que ele possa participar da sociedade tecnológica atual, bem como atitudes e valores sobre as questões ambientais, políticas e éticas relacionadas à ciência e tecnologia. Nessa perspectiva, o ensino de ciências deveria levar o aluno a vivenciar situações que propiciassem o desenvolvimento da capacidade de julgar, avaliar e se posicionar frente às questões sociais que envolvam aqueles aspectos (SANTOS e MORTIMER,1999). De acordo com Driver et al., 1999, p. 36:

[...] aprender ciências não é uma questão de simplesmente ampliar o conhecimento dos jovens sobre os fenômenos - uma prática talvez denominada mais apropriadamente como estudo da natureza - nem de desenvolver ou organizar o raciocínio do senso comum dos jovens. Aprender ciências requer mais do que desafiar as ideias anteriores dos alunos, através de eventos discrepantes. Aprender ciências requer que crianças e adolescentes sejam introduzidos numa forma diferente de pensar sobre o mundo natural e de explica-lo [...].

As diferentes formas de ver, conceber e falar sobre o mundo, podem ser pensadas como diferentes formas de conhecimento, que correspondem a diferentes realidades. Entre estas há uma que se apresenta como a realidade por excelência: aquela da vida cotidiana. Quando alguém desloca sua atenção dessa realidade cotidiana para, por exemplo, o conhecimento científico, uma mudança radical tem lugar em sua consciência. Mesmo, contudo, quando este tipo de mudança radical tem lugar, a realidade cotidiana ainda marca sua presença. Para falar dessas diferentes realidades usamos linguagens variadas, mas todas elas são 
construídas a partir da linguagem da vida cotidiana. Mesmo que se possa empregar linguagens mais sofisticadas - como a Matemática e a Química - é preciso que se estabeleçam relações entre as diferentes realidades, possibilitando sua coexistência num mesmo sujeito que vive num mundo tão diversificado. A própria ciência não é homogênea e pode oferecer múltiplas formas de ver o mundo. Essas ideias podem conviver em uma mesma pessoa, sendo usadas em contextos independentes e não relacionados (MACHADO e MORTIMER, 2010).

Para Machado e Mortimer (2010) aprender Química é também aprender sobre a natureza dessa ciência, seus processos de investigação e seus métodos. A Química pode fornecer ao aluno instrumentos de leitura do mundo e, ao mesmo tempo, desenvolver certas habilidades básicas para ele viver em sociedade.

Segundo Piaget (2010) a criança aprende quando há uma modificação duradoura e equilibrada do comportamento. Há então que se assimilar e adaptar os novos conhecimentos aos anteriores. Nessa perspectiva Piaget salienta a importância do "fazer" do aluno, entendendo que a aprendizagem se dá pela interação entre sujeitos e objeto, numa sequência invariável de estágios, cada um dos quais representando um nível singular de organização cognitiva interna que possibilita e determinados tipos de análise de informações que o sujeito pode realizar. Assim, os indivíduos, ao interagirem com o ambiente, analisam o ocorrido de acordo com o estágio de desenvolvimento cognitivo em que se encontram.

Para levar os estudantes às ideias convencionais da ciência, é essencial a intervenção do professor para orientar observações e disponibilizar as ferramentas e convenções culturais da comunidade científica (BAZZAN et al., 2010).

Na Educação Básica, a área de Ciências da Natureza deve contribuir com a construção de uma base de conhecimentos contextualizada, que prepare os estudantes para fazer julgamentos, tomar iniciativas, elaborar argumentos e apresentar proposições alternativas, bem como fazer uso criterioso de diversas tecnologias. O desenvolvimento dessas práticas e a interação com as demais áreas do conhecimento favorecem discussões sobre as implicações éticas, socioculturais, políticas e econômicas de temas relacionados às Ciências da Natureza (BRASIL, 2018).

No Ensino Médio, a área deve, portanto, se comprometer, assim como as demais, com a formação dos jovens para o enfrentamento dos desafios da contemporaneidade, na direção da educação integral e da formação cidadã. Os estudantes, com maior vivência e maturidade, têm condições para aprofundar o exercício do pensamento crítico, realizar novas leituras do mundo, com base em modelos abstratos, e tomar decisões responsáveis, éticas e consistentes na identificação e solução de situações-problema (BRASIL, 2018).

Quando os alunos concretizam aprendizagens do tipo que lhes possibilita continuar a aprender por toda a vida, por sua própria conta, estarão realizando o que é essencial na escola. Aprender verdadeiramente é tornar-se autônomo nas interações no mundo social e natural, ser participativo e assumir-se sujeito nos contextos em que se atua, ainda que sempre consciente dos limites desta autonomia. Isso significa tornar-se efetivamente cidadão (GALIAZZI; MORAES; ROQUE, 2010). 
Em lugar de pretender que os jovens apenas aprendam o que já sabemos, o mundo deve lhes ser apresentado como campo aberto para investigação e intervenção quanto a seus aspectos sociais, produtivos, ambientais e culturais. Desse modo, a escola os convoca a assumir responsabilidades para equacionar e resolver questões legadas pelas gerações anteriores, valorizando o esforço dos que os precederam e abrindose criativamente para o novo (BRASIL, 2018).

As habilidades e competências que devem ser promovidas no ensino de Química devem estar estreitamente vinculadas aos conteúdos a serem desenvolvidos, sendo parte indissociável desses conteúdos, e devem ser concretizadas a partir dos diferentes temas propostos para o estudo da Química, em níveis de aprofundamento compatíveis com o assunto tratado e com o nível de desenvolvimento cognitivo dos estudantes. Para que se possa ter uma visão mais específica, apresenta-se a metalurgia como um exemplo de abordagem de temas, objetivando o desenvolvimento das competências e habilidades que levam ao fio condutor proposto. Pode-se, no primeiro momento, focalizar o problema da mineração e metalurgia do ferro no Brasil, visando ao desenvolvimento das competências e habilidades dentro do campo da percepção sociocultural e histórica (BRASIL, 2000).

A metalurgia pode ainda ser examinada no contexto de um estudo mais amplo da litosfera. Assim, estudam-se fontes naturais de minérios dos quais se extraem os diferentes metais, os processos químicos envolvidos nessas transformações, as implicações sociais, econômicas e ambientais decorrentes da obtenção e do uso desses metais. Esses estudos deverão ser estruturados de tal forma a permitir o desenvolvimento das competências e habilidades nos três campos (representação e comunicação, compreensão e investigação e percepção social e histórica) propostos nos Parâmetros Curriculares Nacionais (Ensino Médio) - Ciências da Natureza, Matemática e suas Tecnologias (BRASIL, 2000).

Cabe aos sistemas e às escolas adotar a organização curricular que melhor responda aos seus contextos e suas condições: áreas, interáreas, componentes, projetos, centros de interesse etc. Independentemente da opção feita, é preciso romper com a centralidade das disciplinas nos currículos e substituí-las por aspectos mais globalizadores e que abranjam a complexidade das relações existentes entre os ramos da ciência no mundo real. Para tanto, podem ser criadas situações de trabalho mais colaborativas, que se organizem com base nos interesses dos estudantes e favoreçam seu protagonismo (BRASIL, 2018).

\section{RESULTADOS E DISCUSSÃO}

O trabalho aqui apresentado consiste no Produto Educacional da dissertação do Programa de Mestrado Profissional em Química em Rede Nacional (PROFQUI), designado Ensino de Química com abordagem CTS - elaboração e vivência de uma sequência didática com a temática Mineração, e teve como principal foco desenvolver uma aprendizagem efetiva e relacionar a vivência dos alunos com a temática proposta. Foi abordado a importância e os reflexos sociais, econômicos e ambientais da atividade mineradora para a sociedade e em especial para a comunidade de Caeté/MG.

O material associa o conteúdo proposto com as práticas escolares e sociais, através de atividades como trabalhos em grupos, sala de aula invertida, visitas em espaços não formais de educação, aulas práticas 
e atividades avaliativas, entre outras com o objetivo de promover uma alfabetização científica e sociocultural.

Um teste prévio com as primeiras etapas da sequência didática proposta foi aplicado em uma turma do $1^{\circ}$ ano do Ensino Médio de uma escola pública localizada na cidade de Caeté. As demais etapas permaneceram como propostas.

A sequência didática aborda uma proposta de ensino contextualizada e interdisciplinar, sendo composta por nove momentos, descritos a seguir:

- Aula 01 - Apresentação da proposta da pesquisa, abordagem do tema Mineração e distribuição dos conceitos a serem trabalhados - neste primeiro momento da sequência didática, foi realizada a apresentação da proposta da pesquisa relacionando-a com a importância da atividade mineradora para a região, em nosso caso, e para a sociedade. Através de uma conversa informal apresentou-se aos alunos fatos abordados em jornais e na mídia em geral, sobre os desastres ambientais provocados pela Mineração. Os alunos participaram da conversa trazendo experiências e opiniões a respeito do tema Mineração. Em seguida os alunos foram orientados a fazer a pesquisa sobre os conceitos em livros didáticos, revistas e na internet para a confecção e apresentação de cartazes em grupo na aula seguinte. Os grupos foram divididos de maneira que cada um ficasse com cinco integrantes.

- Aula 02 - Confecção dos cartazes pelos alunos e apresentação dos trabalhos para a turma - para a realização dessa atividade os grupos compostos por cinco alunos levaram para a sala de aula uma pesquisa sobre os conceitos relacionados à Mineração como metais, mineral, minério e rochas, imagens e materiais como cartolinas, canetas esferográficas e cola para a confecção dos cartazes que foram previamente solicitados na aula anterior. Os alunos se organizaram em grupos, confeccionaram os cartazes e logo após apresentaram para a turma o trabalho realizado. Após os grupos apresentarem os trabalhos produzidos, os cartazes foram afixados nos corredores da escola e na sala de aula (Figura 02). 
Figura 02: Cartaz sobre Metais

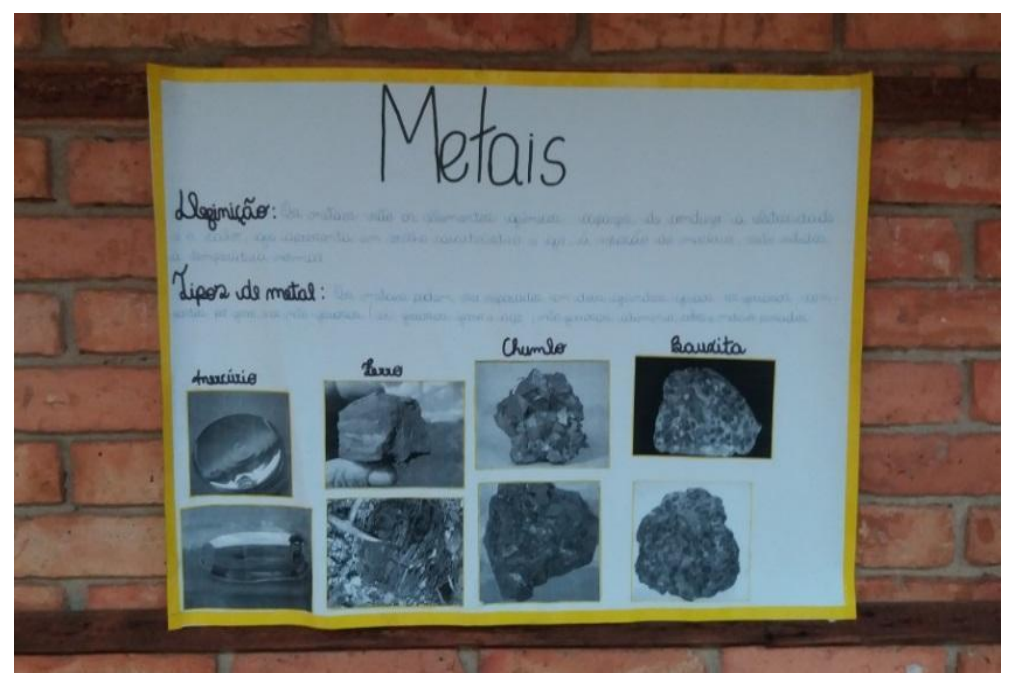

Fonte: A s autoras.

- Aula 03 - Apresentação de vídeos para a reflexão dos alunos sobre os impactos provocados pela Mineração e coleta de dados sobre a opinião dos alunos a respeito dessa ativida$\boldsymbol{d e}$ - O terceiro momento da sequência didática inclui a apresentação de quatro vídeos para estimular a reflexão dos alunos sobre impactos provocados pela mineração. Dois dos vídeos apresentados são da Mineradora Vale do Rio Doce os quais possuem o lema "Evoluir é o melhor caminho, sempre". Vídeos que mostram a presença e a importância de alguns minérios produzidos pela mineradora em histórias emocionantes de algumas pessoas. Os outros dois vídeos são da Produtora Filadélfia, que trazem uma campanha, com a atriz Mariana Ximenes, afirmando a importância de não deixar um dos maiores desastres ambientais do Brasil, o rompimento da barragem de rejeitos na cidade de Mariana/MG, ser esquecido. Nessa aula a exibição dos vídeos tem o objetivo de apresentar aos alunos realidades diferentes em relação à Mineração. Os alunos ao assistirem os vídeos passam a ter opiniões críticas referentes à importância da atividade mineradora para a sociedade e também referente aos grandes impactos ambientais e sócio econômicos provocados e esquecidos pelas mineradoras.

\section{Relatos de alguns alunos sobre a atuação e sobre a importância da Mineração}

\footnotetext{
Aluno A

"Eu sou a favor da mineração caso a empresa se responsabilize pelos danos causados, investindo na restauração do local. A mineração em si causa impactos positivos na sociedade, mas a exploração tem que ser regrada e é preciso ter a consciência de quando parar."
} 


\title{
Aluno B
}

"Não sou a favor, nem contra, pois a mineração tem seus pontos bons e ruins, tanto a cidade e a empresa precisam. Ela gera empregos, renda para as cidades, mas também causa prejuízos como os de Bento Rodrigues ( Mariana) e o de Córrego do Feijão ( Brumadinho)."

\begin{abstract}
Aluno C
"Eu sou contra a mineração. Por mais que ela traga emprego para a cidade os danos causados por uma tragédia são bem maiores. As empresas de mineração só estão pensando nos fins lucrativos, e esquecem de pensar no bem das pessoas. Acaba que os custos com uma tragédia são bem maiores que um método de mineração segura. Destruir cidades, inúmeras mortes, famílias desoladas, destruir o ambiente. Que preço tem isso? Ate quando a vida das pessoas vão ser cartas nas mãos dos grandes empresários. Somos vidas."
\end{abstract}

- Aula 04 - Visita a Litoteca do Serviço Geológico do Brasil - o quarto momento da sequência didática é a realização de uma visita técnica com os alunos à litoteca no Serviço Geológico do Brasil que disponibiliza um rico conjunto de amostragens geológicas. Será solicitado aos alunos um relatório da visita, com questões previamente elaboradas pela docente, no qual deverá será abordado os principais aspectos observados e o que mais despertou interesse durante a visitação.

- Aula 05 - Leitura e interpretação do texto: Beneficiamento do Minério -nesta etapa da sequência didática, será apresentado aos alunos um texto sobre o Beneficiamento do Minério. O texto será lido em conjunto e posteriormente será solicitado a elaboração de um fluxograma sobre o assunto. Para a elaboração do fluxograma a turma será dividida em pequenos grupos, compostos por 03 alunos cada.

- Aula 06 -_Leitura e interpretação do texto: METAIS, SOCIEDADE E AMBIENTE - a proposta desse momento da sequência didática é a leitura e interpretação do texto METAIS, SOCIEDADE E AMBIENTE, disponível no livro Química Cidadã, de Widson Santos e Gerson Mol - volume 03, páginas 269-270 e a aplicação de um questionário sobre o texto. Os alunos serão organizados em duplas, e cada aluno receberá o texto. Será imposto um tempo de 20 minutos para a leitura do texto e logo após os alunos receberão um questionário avaliativo contendo 05 questões discursivas. A sugestão é que, em um outro momento, após 
a correção dos questionários, o professor faça a leitura das respostas que considerou mais adequadas.

- Aula 07 - Aula prática: oxidação de metais -esse momento da sequência didática é uma aula prática sobre a oxidação dos metais. Inicialmente será apresentado aos alunos um texto introdutório sobre o assunto. Após a leitura será dada início aos experimentos e em seguida a discussão e elaboração das respostas das questões propostas. Antes da leitura do texto o professor poderá abordar alguns conceitos a respeito do conteúdo como de oxidação, redução, metal de sacrifício, dentre outros. Nessa aula prática, os resultados dos experimentos não são imediatos, espera-se um intervalo de tempo de cerca de 48 horas. O professor, se considerar conveniente, poderá adiantar o experimento antes e apresentar o resultado experimental obtido para os alunos para os mesmos responderem às questões propostas (Figura 03). O objetivo da prática proposta é trabalhar as reações de oxido-redução, utilizando óxidos resultantes da oxidação de ferro e cobre, bem como a baixa reatividade de outros metais, para a criação de quadros.

Figura 03: Resultados obtidos no experimento realizado - Oxidação dos metais

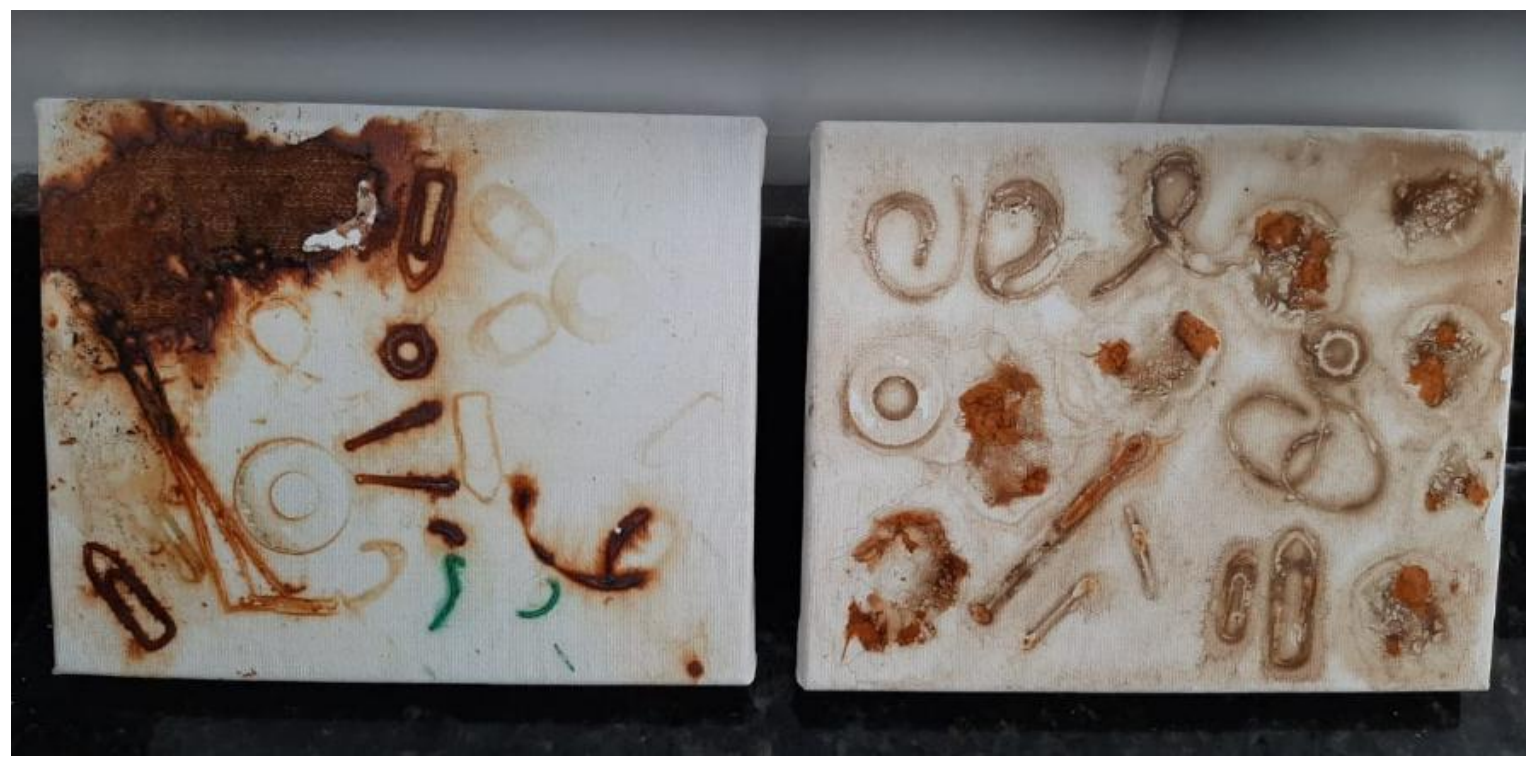

Fonte: As autoras.

- Aula 08 - Aula prática: Extraindo ferro de cereais matinais -por meio de um experimento, propõe-se interligar conceitos químicos e físicos e relacioná-los à área de nutrição, demonstrando, assim, aspectos importantes relativos à interdisciplinaridade das ciências no nosso cotidiano. Incialmente será apresentado aos alunos um texto introdutório sobre o 
assunto. Após a leitura será dada início aos experimentos e em seguida a discussão e elaboração das respostas das questões propostas (Figura 04).

Figura 04: Pó dos flocos de cereal sendo atraídos pelo magneto

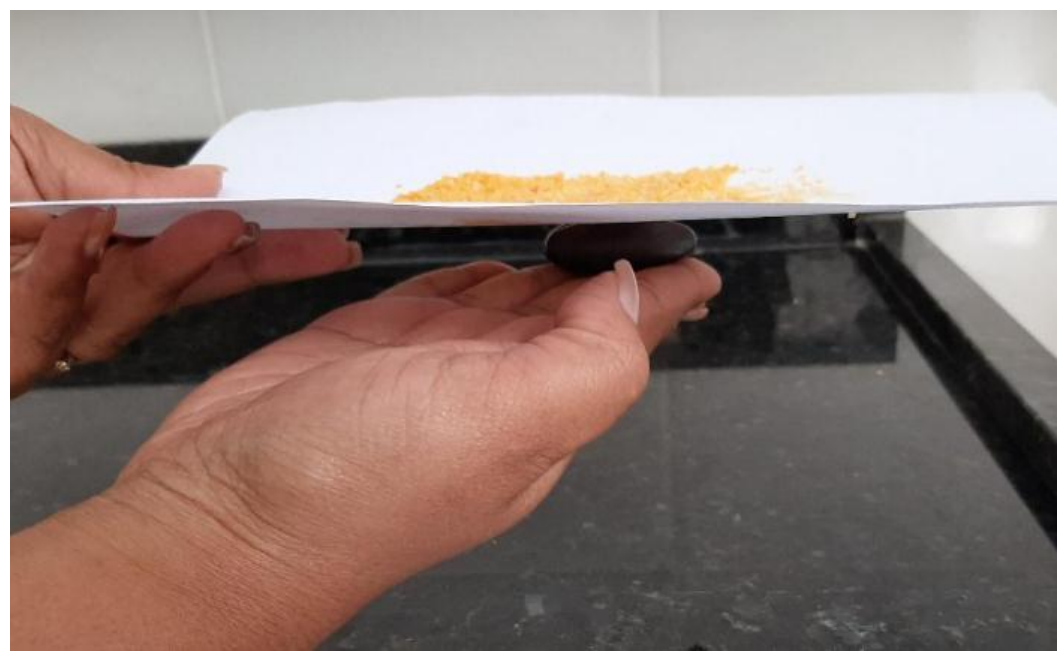

Fonte: As autoras.

- Aula 09 - Aplicação de uma atividade avaliativa para os alunos com questões de vestibulares e ENEM que abordam conceitos como metais, mineração, oxidação dos metais e suas propriedades -nesse momento final será aplicada uma atividade que tem como objetivo verificar quais e quantos objetivos propostos na aplicação de toda a sequência foram cumpridos.

Espera-se que este produto educacional possa contribuir para desenvolver uma visão crítica dos alunos sobre a atuação da atividade mineradora na região e no mundo e sobre as questões ambientais relacionadas a essa atividade

\section{CONSIDERAÇÕES FINAIS}

O ponto de partida do presente trabalho foi um dos maiores desastres ambientais da história, o rompimento da barragem de rejeitos na cidade de Brumadinho/MG. A importância social, ambiental e econômica da atividade mineradora e os seus reflexos, foram as motivações para a elaboração da sequência didática com a temática Mineração.

Elaborei a sequência didática com o objetivo de levar aos alunos, conhecimentos e práticas pedagógicas para ampliarem suas capacidades de aprendizagem tornando-os capazes de interagir 
com criticidade sobre os efeitos da mineração, visto que nosso município possui uma riqueza mineral e muitas vezes estamos envolvidos em eventos relacionados a estas riquezas.

Este trabalho é apenas um despertar para uma construção de práticas pedagógicas que envolvam a comunidade, a escola, as empresas, as famílias as autoridades buscando uma aprendizagem significativa atraindo os alunos em busca de uma sociedade equilibrada respeitando a vida, a cultura e o bem-estar de todos. No mundo atual torna-se imprescindível trabalhar as disciplinas de forma inter e/ou transdisciplinar formando educandos conscientes. Como educadora manifesto meu desejo e perspectivas futuras do trabalho desenvolvido como aliado à educação e a vivência dos alunos, para juntos, construirmos um futuro melhor e promissor.

\section{REFERÊNCIAS}

ARAÚJO, E. R.; FERNANDES, F.. R.. C. Mineração no Brasil: crescimento econômico e conflitos ambientais. Centro de Tecnologia Mineral/ CICP, cap 02, p. 65-68, Rio de Janeiro, 2016.

BAZZAN, A. C.; DRIEMEYER, P. R.; LAUXEN, M. T. C.; MALDANER, O. A.; PRADO, M. C.; ZANON, L. B. Currículo Contextualizado na área Ciências da Natureza e suas Tecnologias: a Situação do Estudo. In: MALDANER, O. A.; ZANON, L B..(org). Fundamentos e Propostas de Ensino de Química para a Educação Básica no Brasil. Ijuí: Unijuí, 2010.

BRASIL. Secretaria de Educação Média e Tecnológica. Parâmetros Curriculares Nacionais (Ensino Médio) - Ciências da Natureza, Matemática e suas Tecnologias, Brasília, 2000.

BRASIL. Ministério da Educação. Bases Nacional Comum Curricular (Ensino Médio), 2018.

CAETÉ, Câmara Municipal de Caeté, Caeté em Revista, Edição Especial 2017

DRIVER, R.; ASOKO, H.; LEACH, J.; MORTIMER, E.; SCOTT, P. Construindo conhecimento na sala de aula. Química Nova na Escola. n.9, p. 31- 40, 1999.

DUARTE, H. A. Ferro - um elemento químico estratégico que permeia história, economia e sociedade. Química Nova, v.42,n.10,p.1146-1153, agosto, 2019

EL-HANI, C. N.; BIZZO, N. M. V. Formas de construtivismo: mudança conceitual e construtivismo contextual. Revista Ensaio, v. 4, n.1, p. 1-25, julho, 2002.

FIGUEIRA, H. V. O.; LUZ, A. B.; ALMEIDA, S. L. M.; Britagem e Moagem. Capítulo 04, p.143210. In: FRANÇA, S. C. A.; LUZ, A. B.; SAMPAIO, J. A. (org). Tratamento de Minérios. $5^{\text {a }}$ edição, Centro de Tecnologia mineral (CETEM) / Ministério da Ciência e Tecnologia (MCT), Rio de Janeiro, 2010.

FREITAS, O.; IZUMI, C.; MACHADO, A. A. Bases Moleculares da absorção do ferro. Revista Alimentos e Nutrição Araraquara. V.16,n. 3.p. 293-298, Jul./Set.,2005.

FONSECA, M. A.; SOBREIRA, F. G.. Impactos físicos e sociais de antigas atividades de mineração em Ouro Preto. Revista Geotecnia, v. 92, p. 5-28, 2001 
GALIAZZI, M. C.; MORAES, R.; RAMOS, M. G. Aprender Química: Promovendo Excursões em Discurso da Química. In: MALDANER, O. A.; ZANON, L. B. (org). Fundamentos e Propostas de Ensino de Química para a Educação Básica no Brasil. Ijuí, Unijuí, 2010.

GERHARDT, T. E.; SILVEIRA, D. T. (Orgs.). Métodos de pesquisa. Porto Alegre: Editora da UFRGS, 2009.

LIMA, J. O. G. Perspectiva de novas metodologias no Ensino de Química. Revista Espaço Acadêmico, nº136, p.95-101, Setembro, 2012

LINS, F. A. F.; LUZ, A. B. Introdução ao tratamento de Minérios. Capítulo 01, p.03-18. In: FRANÇA, S. C. A.; LUZ, A. B.; SAMPAIO, J. A. (org). Tratamento de Minérios. $5^{\text {a }}$ edição, Centro de Tecnologia mineral (CETEM) / Ministério da Ciência e Tecnologia (MCT), Rio de Janeiro, 2010.

MACHADO, A. H.; MORTIMER, E. F. Química para o Ensino Médio: Fundamentos, Pressupostos e o Fazer Cotidiano. In: MALDANER, O. A.; ZANON, L. B. (org). Fundamentos e Propostas de Ensino de Química para a Educação Básica no Brasil. Ijuí, Unijuí 2010.

MACHADO, M. M. M.; RUCHKYS, U. A.. Patrimônio geológico e mineiro do Quadrilátero Ferrífero, Minas Gerais - Caracterização e iniciativas de uso para educação e geoturismo. Boletim Paranaense de Geociências, v.70, p.120-135, 2013.

MARCONDES, M. E. R.; MILARÉ, T.; REZENDE, D. B. Discutindo a Química do Ensino Fundamental através de um caderno escolar de Ciências no Nono Ano. Química Nova na Escola, v. 36, n. 3, p. 231-240, Agosto 2014.

MARCONDES, M. E. R.; SILVA, E. L. Visões de contextualização de professores de Química na elaboração de seus próprios materiais didáticos, Revista Ensaio, v.12, n.01, p.110-118, jan/abril, Belo Horizonte, 2010.

MEDEIROS, M. A. Ferro. Química Nova na Escola, v.32, n.3, p. 208-209, 2010.

PIAGET, J.. Seis estudos de psicologia. 24.ed. Rio de Janeiro: Forense Universitária, 2010.

REZENDE, V. L.. A mineração em Minas Gerais: uma análise de sua expansão e os impactos ambientais e sociais causados por décadas de exploração. Sociedade \& Natureza, v. 28, n. 3, p. 375-384, Uberlândia 2016.

SANTOS, W. L. P, MORTIMER, E. F.. A Dimensão social do ensino de Química: um estudo exploratório da visão de professores. In: Encontro Nacional de Pesquisa em Educação de Ciências, 2. Valinhos, São Paulo,1999.

SILVA, J. P. S. Impactos ambientais causados por mineração. Revista Espaço da Sophia, n. 8, pg.1-13, novembro 2007.

SOARES, L. Barragem de rejeitos. Capítulo 19, p.831-888. In: FRANÇA, Silvia Cristina Alves; LUZ, Adão Benvindo; SAMPAIO, João Alves. (org). Tratamento de Minérios. 5 a edição, Centro de Tecnologia mineral (CETEM) / Ministério da Ciência e Tecnologia (MCT), Rio de Janeiro, 2010 . 
TRINDADE, W, VIEIRA, R. A. O centro histórico de Caeté/MG: entre a preservação e a modernização (1967-1971). Revista do Curso de História da Estácio BH ISSN 23170174. n.11, Belo Horizonte, 2018. 